\title{
Do lipid profile predict subclinical Cushing's Syndrome in patients with
} adrenal incidentalomas?

\author{
Mintziori G, Georgiou Th, Siolos A, Adamidou F, Efstathiadou Z, Panagiotou A, \\ Anagnostis $\mathrm{P}$, Kita $\mathrm{M}$
}

Department of Endocrinology, Ippokratio General Hospital, Thessaloniki, Greece

\section{Introduction}

Adrenal Incidentalomas (Als) have been associated with an increased risk of metabolic syndrome and dyslipidemia, though evidence regarding the latter is limited and, sometimes conflicting (1-3).

Lipid abnormalities in patients with Als have been described to be associated with subclinical hypercortisolism.

Our aim was to test if lipid profile in patients with adrenal incidentalomas may predict subclinical Cushing's Syndrome (sCS).

\section{Material and Methods}

A prospective, cohort study was conducted at the Department of Endocrinology, Ippokratio General Hospital of Thessaloniki, Greece.

Ninety-four patients $(n=94)$ with adrenal incidentalomas (Als) were included in a prospective cohort study.

All patients were followed up for three years and alternations of their hormonal and lipid profiles were recorded. IBM SPSS Statistics V20 were used.

\section{Results}

The 94 patients (25 men and 69 women) of our cohort harbored 111 Als.

There were no differences between patients with SCS and those without, with respect to their baseline lipid profile and blood pressure (Fig 1).

\begin{tabular}{|l|l|l|l|}
\hline & $\begin{array}{c}\text { Patients } \\
\text { with } \\
\text { subclinical } \\
\text { Cushing }\end{array}$ & $\begin{array}{c}\text { Patients without } \\
\text { subclinical } \\
\text { Cushing }\end{array}$ & $\begin{array}{c}\text { P } \\
\text { value }\end{array}$ \\
\hline Cholesterol & $223 \pm 12$ & $205 \pm 4$ & 0.195 \\
\hline LDL & $137 \pm 11$ & $124 \pm 4$ & 0.267 \\
\hline HDL & $54 \pm 2$ & $55 \pm 2$ & 0.809 \\
\hline Triglycerides & $153 \pm 13$ & $130 \pm 6$ & 0.245 \\
\hline Non-HDL & $169 \pm 13$ & $150 \pm 4$ & 0.176 \\
\hline Total (N) & 9 & 85 &
\end{tabular}

Fig 1. Patients with and without Subclinical Cushing Syndrome

33 patients $(35 \%)$ were treated with statins at the time of diagnosis

There were no differences among patients with and without $\mathrm{sCs}$ regarding the use of statins at the time of diagnosis.
Non-HDL concentrations decreased over time (Repeated Measures ANOVA, $p=0.013$ ), despite patients' Body Mass Index (BMI) remaining unchanged

Logistic regression revealed that the only predictor of SCS is the size of adrenal incidentalomas, as calculated by computed tomography (CT).

\section{Conclusion}

The current study demonstrated that lipid profile at baseline or during follow up cannot predict sCS in patients with adrenal incidentalomas.

The improvement of patients' lipid profile during follow up is probably due to better medical management.

\section{References}

1. Di Dalmazi G, Pasquali $R$, Beuschlein $F$, Reincke M. Subclinical hypercortisolism: a state, a syndrome, or a disease? Eur J Endocrinol. 2015 Oct;173(4):M61-71.

2. Zografos GN, Perysinakis I, Vassilatou E. Subclinical Cushing's syndrome: current concepts and trends. Hormones (Athens). 2014 Jul-Sep;13(3):323-37

3. Masserini B, Morelli V, Palmieri S, EllerVainicher C, Zhukouskaya V, Cairoli E, Orsi E, Beck-Peccoz P, Spada A, Chiodini I. Lipid abnormalities in patients with adrenal incidentalomas: role of subclinical hypercortisolism and impaired glucose metabolism. J Endocrinol Invest. 2015 Jun;38(6):623-8

\section{8}

